- Mã số KC.10/11-15, Nghiêm thu năm 2016.

6. Atik FA, Couto CF, Tirado FP, et al. Addition of long-distance heart procurement promotes changes in heart transplant waiting list status. Rev Bras Cir Cardiovasc. 2014;29(3):344-349. doi:10.5935/1678-9741.20140046

7. Gaffey AC, Chen CW, Chung JJ, et al. Extended distance cardiac allograft can successfully be utilized without impacting longterm survival. The Journal of Heart and Lung Transplantation. 2017;36(9):968-972. doi: 10.1016/j.healun.2017.04.002

8. Charniot J-C, Bonnefont-Rousselot D,
Albertini J-P, et al. Oxidative Stress Implication After Prolonged Storage Donor Heart with Blood Versus Crystalloid Cardioplegia and Reperfusion Versus Static Storage. Journal of Surgical Research. 2010;160(2):308-314. doi: 10.1016/j.jss.2009.03.023

9. Caenegem OV, Beauloye $C$, Bertrand $L$, et al. Hypothermic continuous machine perfusion enables preservation of energy charge and functional recovery of heart grafts in an ex vivo model of donation following circulatory death. Thoracic Surgery.:6.

\title{
ĐÁNH GIÁ KẾT QUẢ ĐIỀU TRI UNG THƯ Cổ TỬ CUNG GIAI ĐOAN FIGO IB1-IIA1 BẰNG PHƯƠNG PHÁP PHẪU THUÂTT TẠI BỆNH VIỆN K
}

\section{TÓM TẮT}

Nghiên cứu của chúng tôi đánh giá kết quả điều trị của nhóm bệnh nhân ung thư cổ tử cung giai đoan FIGO IB1-IIA1 được phẫu thuật triệt căn ngay từ đầu tại bênh viên $K$. Đối tượng và phương pháp nghiền cứu: Chúng tôi tiến hành nghiên cứu hồi cứu trên 158 bênh nhân ung thư cổ tử cung giai đoan FIGO IB1-IIA1, được phẫu thuật cắt tử cung triệt cằn ngay từ đầu tại bệnh viện $K$ từ tháng $1 / 2016$ đến 1/2019. Các chỉ tiêu nghiển cứu bao gồm một số đăc điểm lâm sàng, cận lâm sàng và kết quả điều trị. Kết quả: Tuổi trung bình: $50 \pm 10,4$ tuổi. Ra máu âm đạo sau quan hệ tình dục là triệu trứng thường găp nhất (70,3\%). Carcinoma tế bào vảy là thể giải phẩu bệnh phỗ biến nhất $(77,2 \%)$. Tỷ lệ di căn hạch chậu sau phẫu thuât là $18,4 \%$. Tỷ lể bểnh nhân điều tri bổ trơ sau phẫu thuât là $45,6 \%$. Tỷ lệ sống thêm toàn bộ 3 năm, 5 năm lần lượt là: $94,8 \%$ và $88,8 \%$. Tỷ lệ sổng thêm không bệnh 3 năm, 5 năm lần lượt là: $87,2 \%$ và $82,5 \%$. Biến chứng cấp tính sau phấu thuật hay gặp nhất là bí tiểu $(12,7 \%)$. Kết luận: Phẫu thuật triệt căn chỉ định cho giai đoan ung thư cổ tử cung giai đoạn FIGO IB1-IIA1 có kết quả sống thêm tốt, an toàn và các biến chứng trong giới hạn chấp nhận được.

Tư khóa: Ung thư cổ tử cung, cắt tử cung triệt căn, sống thêm.

\section{SUMMARY \\ RESULTS OF SURGERY FOR CERVICAL CANCER FIGO IB1-IIA1 AT VIETNAM NATIONAL CANCER HOSPITAL}

Subject: Our study evaluated the outcomes of cervical cancer patients with FIGO stage IB1-IIA1 who underwent radical surgery at the time of diagnosis at

\section{*Bênh viên $K$}

Chịu trách nhiệm chính: Nguyễn Trọng Diệp

Email: drtrongdiep@gmail.com

Ngày nhận bài: 3.8.2021

Ngày phản biên khoa họ: 4.10 .2021

Ngày duyệt bài: 12.10.2021
Vietnam National Cancer Hospital. Method: We conducted a retrospective study on 158 cervical cancer patients with FIGO stage IB1-IIA1, who received radical hysterectomy from January 2016 to January 2019. Patients were assessed for clinical features and treatment outcome. Results: Mean age: $50 \pm 10,4$ years old. Vaginal bleeding was the most common symptom (70.3\%). The most common histopathology was squamous cell carcinoma $(77.2 \%)$. The rate of pelvic lymph node metastasis was $18.4 \%$. The portion of patients received postoperation adjuvant treatment was $45.6 \%$. The rate of overall survival at 3 years, 5 years was $94.8 \% ; 88.8 \%$, respectively. The percent of disease-free survival at 3 years, 5 years was $87.2 \%$; $82.5 \%$, respectively. The most common acute complication after surgery was dysfuntion bladder $(12,7 \%)$. Conclusion: Radical hysterectomy indicated for cervical cancer FIGO IB1-IIA1 has good survival outcomes, safety and acceptable complications.

Key words: Cervical cancer, radical hysterectomy, survival.

\section{I. ĐẶT VẤN ĐỀ}

Ung thư cổ tử cung là bệnh lý ác tính thường gặp, phổ biến đứng hàng thứ hai trong ung thư phụ khoa, thứ tư trong tổng số ung thư ở nữ giớ [1]. Về điêuu trị, phẫu thuật và xạ trị được coi là 2 vũ khí chính có thể điều trị triệt căn, vai trò của hóa chất và điều trị đích là hạn chế. Giai đoạn FIGO IB-IIA là giai đoan u khu trú tai chỗ, tai vùng, có thể điều trị bằng phẫu thuật triệt căn khởi đâu, hay xạ trị tiền phẫu sau đó phẫu thuật, hay xạ trị triệt căn, với tỷ lệ sống thêm tương đương nhau, chỉ khác nhau về các biến chứng [2]. Ưu điểm của phẫu thuật triệt căn là: bảo tôn được chức năng buồng trứng ở phụ nữ trẻ, cho phép đánh giá chi tiết và chính xác mức độ xâm lấn, tình trạng di căn hạch, một số lượng bệnh nhân không cân xạ trị sau mồ có thể tránh các biến chứng do xạ trị. 
Tại bệnh viện $\mathrm{K}$, ung thư cổ tử cung giai đoạn IB-IIA đã được điều trị hiệu quả với phác đồ xạ trị tiền phẫu rồi phẫu thuật trong nhiều năm với kết quả khả quan, nghiên cứu Nguyễn Văn Tuyên cho kết quả sông thêm 5 năm ở giai đoạn IB-IIA, u dưới $4 \mathrm{~cm}$ là $85,1 \%$, tuy nhiên các biến chứng còn cao do cộng dồn cả hai phương pháp xa trị và phẫu thuậtt [3]. Kể từ năm 2009 tại bệnh viện $K$ chúng tôi bước đầu chuyển sang phẫu thuật triệt căn ngay từ đầu cho nhóm bệnh nhân ung thư cổ tử cung giai đoạn IB1-IIA1. Để đánh giá hiệu quả của phương pháp điều trị này, chúng tôi thực hiện đề tài: "Đánh giá kết quả điều trị ung thư cổ tử cung giai đoạn FIGO IB1IIA1 bằng phương pháp phẫu thuật tại bệnh viện K" với 2 mục tiêu:

1. Mô tả một số đặc điểm lâm sàng, cận lâm sàng ung thu' cố tử cung giai đoạn FIGO IB1IIA1 được phẫu thuật triệt căn ngay từ đầu tại bệnh viện $K$ từ tháng 1 năm 2016 đến tháng 1 năm 2019.

2. Đánh giá kêt quả điều trị ung thư cổ tủ cung giai đoạn FIGO IB1-IIA1 bằng phương pháp phẩu thuật của nhóm bệnh nhân nghiên cứu.

\section{II. ĐỐI TƯỢNG VÀ PHƯƠNG PHÁP NGHIÊN CỨU}

2.1. Đối tượng nghiên cứu. Bệnh nhân được chẩn đoán xác định ung thư cổ tử cung giai đoan FIGO IB1-IIA1, được điêu trị khởi đâu bằng phẩu thuật triêtt căn tai khoa Ngoại Phụ Khoa, bệnh viện $K$ từ tháng 1/2016 - tháng 1/2019.

2.1.1. Tiêu chuẩn chọn bệnh nhân

- Ung thư cổ tử cung giai đoạn IB1-IIA1 (FIGO 2009).

- Chẩn đoán xác định bằng mô bệnh học là ung thư biểu mô cổ tử cung

- Phẫu thuật triệt căn typ C1 đường bụng ngay từ đầu tại bệnh viện $\mathrm{K}$.

2.1.2. Tiêu chuẩn loại trừ

- Bệnh nhân mắc các bệnh cấp và/hoặc mạn tính có nguy cơ tử vong gần.

\subsection{Phương pháp nghiên cứu}

2.2.1. Thiết kế nghiên cứu: Nghiên cứu mô tả hồi cứu.

2.2.2. Cõ̃ mẫu: Trong nghiên cứu của chúng tôi có 158 bệnh nhân đủ điều kiện tham gia nghiên cứu.

2.2.3. Phương pháp thu thập số liệu

- Thu thập số liệu theo một mẫu bệnh án nghiên cứu thống nhất: thông tin đặc điểm lâm sàng, cận lâm sàng dựa vào hồ sơ bệnh án lưu trữ. Thổng tin kết quả điều trị dựa trên khám lại bệnh nhân định kỳ, gọi điện.

2.2.4. Các biến số thu thập và tiêu chí

\section{đánh giá}

*Các đặc điểm lâm sàng, cận lâm sàng:

Tuổi, triệu chứng cơ năng, thể giải phẫu bệnh, tình trạng di căn hạch sau mổ, xâm lấn paramètre, xâm lấn vành âm đạo

*Kết quả điều trị

- Phương pháp điều trị: phẫu thuât đơn thuần, phẫu thuật + xa trị bổ trợ, phẫu thuật + hóa xa trị bổ trợ, hóa chất bổ trợ.

- Kết quả sống thêm: Sống thêm không bệnh và sống thêm toàn bộ 3 năm, 5 năm.

- Các biến chứng của phẫu thuật

2.2.7. Phương pháp phân tích và xử lý số liệu. Số liệu phân tích trên phần mềm SPSS 20.0

III. KẾT QUẢ NGHIÊN CỨU

3.1. Một số đặc điểm lâm sàng, cận lâm sàng của đối tượing nghiên cứu

Bảng 1: Một số đặc điểm lâm sàng, cận lâm sàng của đối tượng nghiên cứu

\begin{tabular}{|c|c|c|}
\hline Đặc điểm & $\begin{array}{c}\text { Số BN } \\
(\mathbf{N}=158)\end{array}$ & Tỷ lệ \% \\
\hline Tuổi trung bình & $\begin{array}{l}50 \pm 10,4 \\
50,0 \pm 10,4\end{array}$ & $\begin{array}{l}(20-70) \\
(25-74)\end{array}$ \\
\hline \multicolumn{3}{|c|}{ Lý do vào viện } \\
\hline $\begin{array}{c}\text { Ra máu âm đạo sau } \\
\text { quan hể }\end{array}$ & 111 & 70,3 \\
\hline Ra khí hư hồi bấn & 22 & 13,9 \\
\hline Ra máu sau mãn kinh & 20 & 12,7 \\
\hline Khám sức khỏe đinh kỳ & 5 & 3,2 \\
\hline \multicolumn{3}{|c|}{ Giải phấu bệnh } \\
\hline Carcinoma vảy & 122 & 77,2 \\
\hline Carcinoma tuyến & 22 & 13,9 \\
\hline Thế khác & 14 & 9,9 \\
\hline \multicolumn{3}{|c|}{ Di căn hạch chậu } \\
\hline Có & 29 & 18,4 \\
\hline Không & 129 & 81,6 \\
\hline
\end{tabular}

Nhận xét: - Tuối trung bình: $50 \pm 10,4$ tuối, thấp nhất là 25 tuổi, cao nhất 74 tuổi.

- 96,8\% bệnh nhân đi khám có triệu chứng lâm sàng, trong đó ra máu âm đạo sau quan hệ tình dục là triệu trứng thường gặp nhất $(70,3 \%)$.

- Carcinoma tế bào vảy là thể giải phẫu bệnh phổ biến nhất $(77,2 \%)$.

- Tỷ lệ di căn hạch chậu sau phẫu thuật là 18,4\%.

3.2. Kết quả điều trị

3.2.1. Phương pháp điều trị

Bảng 2: Phương pháp điều trị

\begin{tabular}{|c|c|c|}
\hline Phương pháp điều trị & Số BN & Tỷ lệ \% \\
\hline Phấu thuật đơn thuần & 86 & 54,4 \\
\hline Có điêu trị bổ trợ & 72 & 45,6 \\
\hline Tống & $\mathbf{1 5 8}$ & $\mathbf{1 0 0 , 0}$ \\
\hline
\end{tabular}

Nhận xét: Tỷ lệ bệnh nhân điêu trị bố trợ sau phẫu thuật là $46,6 \%$. 
3.2.2. Thời gian sống thêm

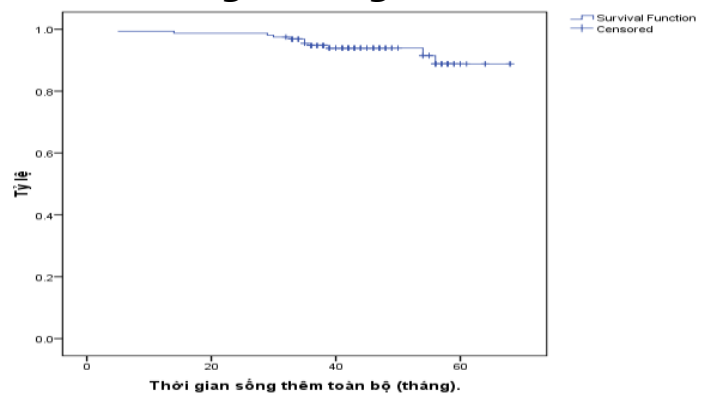

Biểu đồ 1: Sống thêm toàn bộ

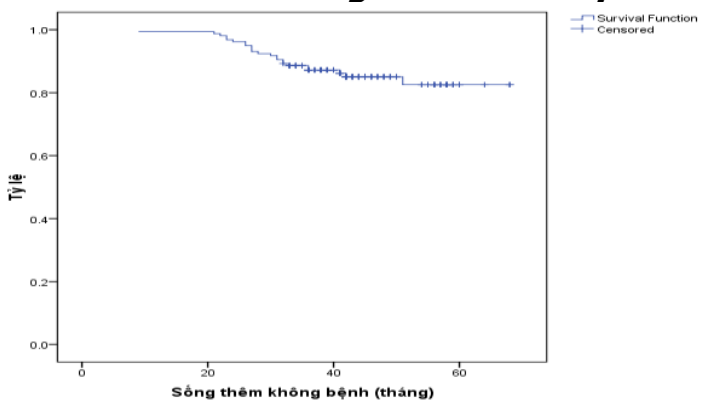

Biểu đồ 2: Sống thêm không bênh

Nhânn xét: - Tỷ lệ sống thêm toàn bộ 3 năm, 5 năm lần lượt là: 94,8\% và $88,8 \%$.

- Tỷ lệ sống thêm không bệnh 3 năm, 5 năm lần lượt là: $86,6 \%$ và $81,9 \%$.

\subsubsection{Biến chứng điêuu trị}

Bảng 3: Các biến chứng của phẫu thuật \begin{tabular}{|l|l|l|}
\hline Biến chứng & Số lượng & Tỉ lệ \%
\end{tabular} Biến chứng sớm

\begin{tabular}{|c|c|c|}
\hline Bí tiếu & 20 & 12,7 \\
\hline Huyết khối tĩnh mạch & 1 & 0,6 \\
\hline Nhiêm trùng tiết niệu & 5 & 3,5 \\
\hline Rò niệu quản & 1 & 0,6 \\
\hline \multicolumn{2}{|c|}{ Biến chứng muộn } \\
\hline Tiểu không tự chủ & 2 & 1,3 \\
\hline Hẹp niệu quản & 2 & 1,5 \\
\hline Bán tắc ruột, tắc ruột & 4 & 3,7 \\
\hline Phù bạch huyết & 10 & 6,3 \\
\hline Nang bạch huyết & 1 & 0,6 \\
\hline Tề bì chân & 1 & 0,6 \\
\hline
\end{tabular}

Nhận xét: Biến chứng cấp tính sau phầu thuật hay gặp nhất là bí tiểu, $12,7 \%$.

\section{BÀN LUẬN}

*Một số đặc điểm lâm sàng, cận lâm sàng của đối tượng nghiên cứu. Trong nghiên cứu của chúng tôi, tuổi trung bình của bệnh nhân là $50 \pm 10,4$ tuổi. Kết quả này phù hợp với kết quả của các nghiên cứu khác. Nghiên cứu của Nguyễn Văn Hà [4], Võ Văn Kha [5] có tuổi trung bình lần lượt là 50,4 tuổi; 49 tuổi [4], [5]. Hầu hết các bệnh nhân trong nghiên cứu của chúng tôi đến khám bệnh vì có triệu trứng bất thường với các triệu trứng phổ biến nhất là ra máu âm đạo sau quan hệ tình dục $(70,3 \%)$, chỉ có 5 bệnh nhân phát hiện tình cờ qua khám sức khỏe định kỳ $(3,2 \%)$.

Về đặc điểm mô bệnh học: thể mô bệnh học phổ biến nhất trong nghiên cứu chúng tôi là ung thư biểu mô tế bào vảy $(77,2 \%)$, sau đó đến ung thư biểu mô tuyến (13,9\%). Đối chiếu với các nghiên cứu khác cho thấy tỷ lệ ung thư biểu mô vảy chiếm đa số, tuy nhiên trong nghiên cứu của chúng tôi tỷ lệ ung thư biểu mô tuyến chiếm tỷ lệ thấp hơn, nghiên cứu của Nguyễn Văn Hà [4] là $30 \%$, của nguyễn Quốc Trực là $25 \%$ [6]. Xu hướng gần đây các thống kê cũng cho thấy tỷ lệ ung thư biểu mô tuyến ngày càng gia tăng trong ung thư cổ tử cung.

Trong nghiên cứu của chúng tôi cho thấy tỷ lệ di căn hạch chậu sau phẫu thuật đối với giai đoạn IB1-IIA1 là 18,4\%, kết quả này tương đương với nghiên cứu của Võ Văn Kha là $19,8 \%[5]$, thấp hơn so với nghiên cứu của Ho là 23,4\% [7], của Nguyễn Văn Tuyên là 21,1\% [3].

* Kết quả điều trị. Trong nghiên cứu chúng tôi $100 \%$ bệnh nhân được phẫu thuật triệt căn ngay từ đầu, trong đó 86 bệnh nhân được phẫu thuật đơn thuần $(54,4 \%)$, còn lại $45,6 \%$ được điều trị bổ trợ sau phấu thuật.

Về các biển chứng sau phẫu thuật cắt tử cung triệt căn trong ung thư cổ tử cung trong nghiên cứu chúng tôi chủ yếu là các biến chứng sớm, trong đó bí tiểu sau mổ chiếm tỷ lê $12,7 \%$. Biến chứng hay gặp nhất sau phẫu thuật cắt tử cung triệt căn là các biến chứng tiết niệu, trong đó phổ biến nhất là rối loạn chức năng bàng quang. Theo các nghiên cứu tỷ lệ này biến thiên trong khoảng từ $12-85 \%$, phụ thuộc vào phương pháp đánh giá chức rối loạn chức năng bàng quang, khoảng thời gian theo dôi, mức độ cắt triệt căn và có bảo tồn hay không bảo tồn tối đa các nhánh thần kinh chậu-hạ vị chi phối bàng quang.

Trong nghiên cứu của chúng tôi, tỷ lệ sông thêm toàn bộ 3 năm, 5 năm lần lượt là: $94,8 \%$ và $88,8 \%$.Tỷ lệ sống thêm không bệnh 3 năm, 5 năm lần lượt là: $86,6 \%$ và $81,9 \%$. Tỷ lệ sống thêm toàn bộ 5 năm trong nghiên cứu của chúng tôi gần tương đương với nghiên cứu của SanGang Wu 87,7\% [2], Nguyễn Văn Tuyên là $85,1 \%$ [3], F.Landoni là $83 \%$ [8].

\section{KẾT LUẬN}

Nghiên cứu của chúng tôi cho thấy phẫu thuật triệt căn ngay từ đầu được chỉ định cho giai đoạn ung thư cổ tử cung giai đoạn FIGO 
IB1-IIA1 có kết quả sống thêm tốt, an toàn và các biến chứng trong giới hạn chấp nhận được.

\section{TÀI LIÊU THAM KHẢO}

1. J. Ferlay, I. Soerjomataram, R. Dikshit, et al. (2015), "Cancer incidence and mortality worldwide: sources, methods and major patterns in GLOBOCAN 2012", Int J Cancer, 136(5), tr. E359-86.

2. San-Gang Wu, Wen-Wen Zhang, Zhen-Yu He, et al (2017), "Comparison of survival outcomes between radical hysterectomy and definitive radiochemotherapy in stage IB1 and IIA1 cervical cancer", Cancer Manag Res. 2017; 9: 813-819.

3. Nguyễn Văn Tuyên. (2008), "Nghiên cứu điều tri ung thư cổ tứ cung giai đoạ IB - II bằng phương pháp phâu thuật kết hợp với xạ trị và một số yếu tố tiên lượng", Luận án Tiến sỹ Y học, Học viên Quân Y.

4. Nguyển Văn Hà (2016), "Đánh giá kết quả điều trị ung thư cổ tử cung giai đoạn IB1 bằng phẫu thuật triệt căn", Luân văn tốt nghiệp bác sỹ nội trú, Đại học Y Hà Nội.

5. Võ Vằn Kha, Võ Đăng Hùng, Huỳnh Quyết Thắng và các công sự. (2009), "Nghiên cứu điều trị ung thư cổ tử cung giai đoạn IB-IIA bằng phâuu thuật đầu tiên tại bệnh viên đa khoa Cần Thơ ", Y hoc TंP Hồ Chí Minh, 10(4).

6. Nguyển Quốc Trực, Tạ Thanh Liêu, Phạm Văan Bưng và các cộng sự. (2006), "Điều trị phấu thuât ung thư cồ tư cung giai đoạn IB1", Y hoc TP Hồ Chí Minh, 10(4).

7. C. M. Ho, T. Y. Chien, S. H. Huang, et al (2004), "Multivariate analysis of the prognostic factors and outcomes in early cervical cancer patients undergoing radical hysterectomy", Gynecol Oncol, 93(2), pp. 458-64.

8. F. Landoni, A. Maneo, A. Colombo và các cộng sự. (1997), "Randomised study of radical surgery versus radiotherapy for stage Ib-IIa cervical cancer", Lancet, 350(9077), tr. 535-40

\title{
ĐÁNH GIÁ KẾT QUẢ PHẪU THUÂTT U TUYẾN GIÁP KHÔNG ĐẶT DẪN LƯU TẠI BỆNH VIỆN K
}

\author{
Phạm Văn Hoàn ${ }^{1}$, Nguyễn Văn Hiếu ${ }^{1}$, Nguyễn Xuân Hậu ${ }^{1}$, \\ Ngô Xuân Quý2, Ngô Quốc Duy ${ }^{2}$
}

\section{TÓM TẮT}

Mục tiêu nghiên cứu: Đánh giá kết quả phẫu thuật u tuyến giáp không đặt dẫn lưu tại bệnh viện $\mathrm{K}$ giai từ năm 2019 đến 2021. Đối tượng và phướng pháp nghiên cứu: Nghiên cứu mô tả cắt ngang, trên các bênh nhân u tuyến giáp được phẫu thuật không đặt dần lưu tại bệnh viện $\mathrm{K}$ từ T1/2019-T8/2021. Theo dỗi các biến chứng sau phầu thuật (tụ dịch, tụ máu, chảy máu, suy cận giáp, nói khàn), mức độ đ̛̣u sau phẫu thuật, thời gian nằm viện. Kết quả: Phẫu thuật không dẫn lưu trền 130 bệnh nhân, tuổi trung bình là $43.5 \pm 10.9$ tuổi. Biến chứng sau mổ ghi nhần $6.9 \%$ bệnh nhân có tu dịch, $6.2 \%$ nói khàn tam thời và $4.6 \%$ suy cận giáp tạm thời, $3.8 \%$ tu máu sau mổ, $0.8 \%$ có chảy máu cần mổ lại. Mức độ đau sau phấu thuật trung bình ngày 0 là $3.18 \pm 0.41$, ngày 1 là $2.4 \dot{8} \pm 0.56$. Thời gian nằm viên trung binh là 4.78 0.76 . Kết luận: Phẫu thuật không đặt dẫn lưu trong các trường hợp u tuyến giáp không kèm theo vét hạch cổ bên an toàn, rút ngắn thời gian nằm viện, thuận tiện cho bệnh nhân trong quá trình hậu phẩu, biến chứng sau phẫu thuật xảy ra với tỷ lệ thẩp, đa phân tự hổi phục, không có trường hợp nằo kéo dài quá 6 tháng.

Từ khóa: U tuyến giáp, phẫu thuật, không dẫn lưu.

${ }^{1}$ Trường Đại học Y Hà Nọi

${ }^{2}$ Bênh viên $K$ cơ sở Tân Triều

Chịu trách nhiệm chính: Phạm Văn Hoàn

Email: rainstorm1108@gmail.com

Ngày nhân bài: 9.8.2021

Ngày phản biên khoa hoc: 5.10 .2021

Ngày duyệt bài: 14.10.2021

\section{SUMMARY}

EVALUATION OF THYROID SURGERY RESULTS WITHOUT DRAINAGE AT VIET

NAM NATIONAL CANCER HOSPITAL

Objective:To evaluate the outcomes of thyroid surgery without drainage at Viet Nam national cancer hospital from 2019 to 2021 . Materials and method: A cross-sectional descriptive study, on thyroid tumor patients who underwent surgery without drainage at $\mathrm{K}$ hospital from $1 / 2019$ to $8 / 2021$. Monitor postoperative complications (fluid collection, hematoma, bleeding, hypoparathyroidism, hoarseness, pain level after surgery, hospital stay). Results: Surgery without drainage on 130 patients, the mean age of patients in the study was $43.5 \pm 10.9$ years old. Postoperative complications recorded $6.9 \%$ of patients with fluid collection, $6.2 \%$ of patients with temporary hoarseness and $4.6 \%$ of temporary hypoparathyroidism, $3.8 \%$ of postoperative hematoma, $0.8 \%$ of bleeding requiring reoperation. The mean postoperative pain on day 0 was $3.18 \pm 0.41$, day 1 was $2.48 \pm 0.56$. The mean hospital stay was $4.78 \pm 0.76$. Conclusions: Surgery without drainage in cases of thyroid tumors without associated cervical lymph node dissection is safe, shortens hospital stay and convenient for patients in the postoperative period, bleeding complications that require reoperation only occur in $0.8 \%$ of patients, other complications after surgery mostly resolved spontaneously, with no cases lasting > 6 months.

Keywords: Thyroid tumor, surgery, without drainage.

\section{I. ĐẠT VẤN ĐỀ}

